\title{
A Near-Isotropic Proton-Conducting Porous Graphene Oxide Membrane
}

Serubbabel Sy, ${ }^{1,+}$ Gaopeng Jiang,,${ }^{1+}$ Jing Zhang, ${ }^{1}$ Hadis Zarrin, ${ }^{2}$ Timothy Cumberland, ${ }^{1}$ Salah Abureden, ${ }^{1}$ Aiping $\mathrm{Yu},{ }^{1}$ Zhongwei Chen ${ }^{1 *}$

1. Department of Chemical Engineering, University of Waterloo, Ontario, N2L 3G1, Canada

2. Department of Chemical Engineering, Ryerson University, Toronto, Ontario, M5B 2K3, Canada

* Tel. 1-(519)-888-4567 Ext: 38664, Email: zhwchen@uwaterloo.ca 


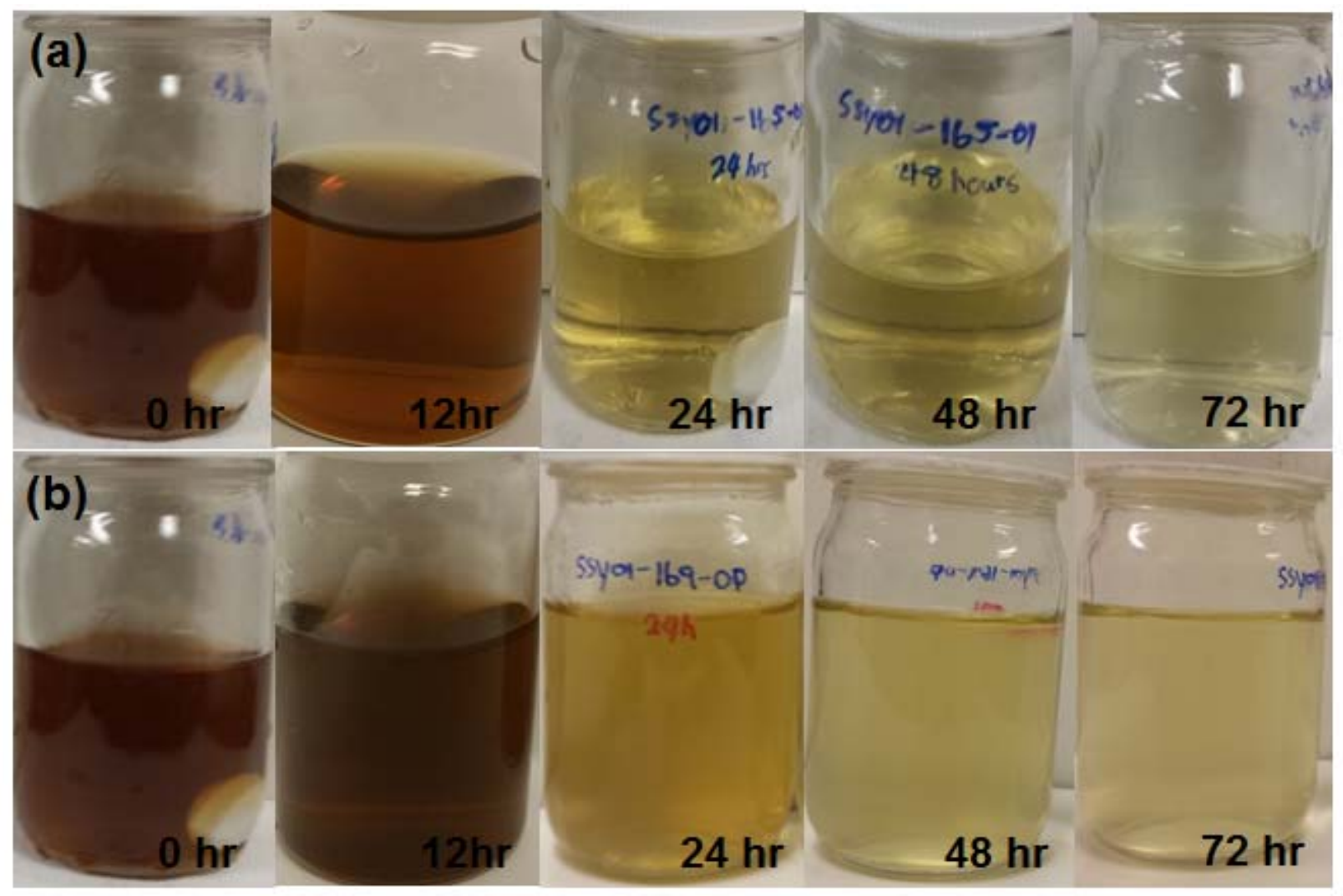

Figure S1. Digital pictures of GO suspension under the treatment of (a) SA-Fenton's reaction and (b) normal Fenton's reaction for different duration 


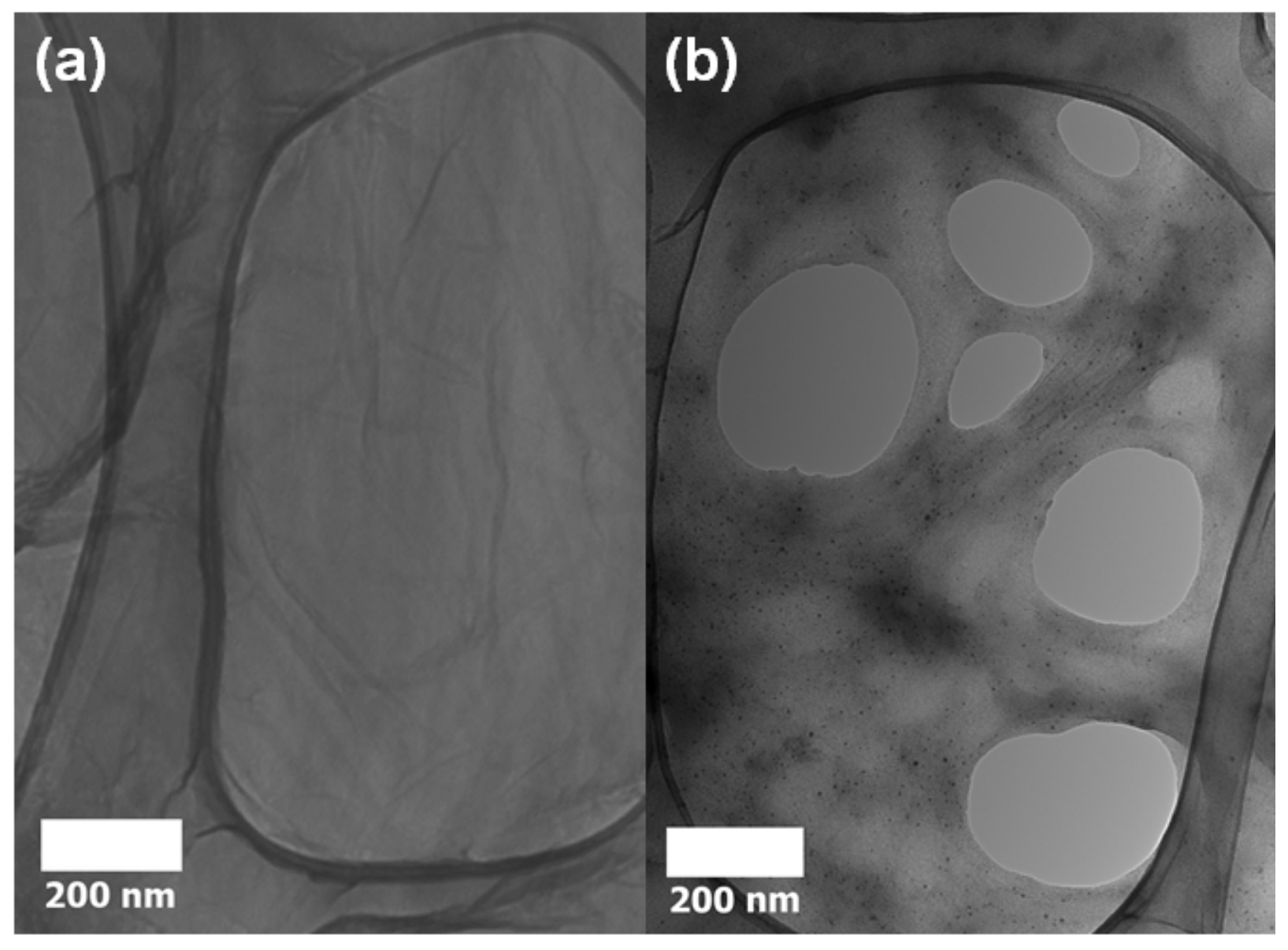

Figure S2. TEM images of GO nanosheets after (a) normal and (b) sonication-assisted Fenton's reaction for 16h. 

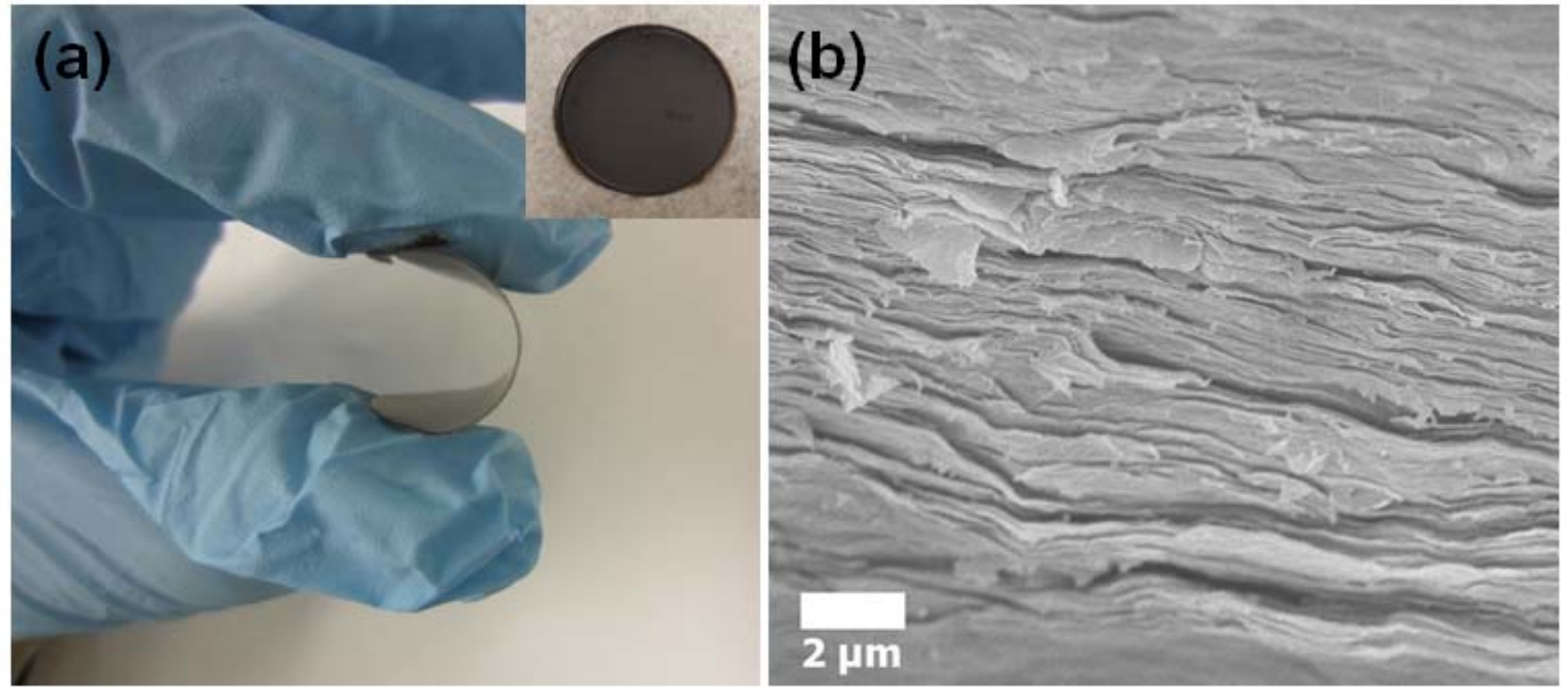

Figure S3. (a) The digital picture of GO membrane (insert: image of flat membrane) and (b) cross-section SEM image of GO membrane. 
(a)

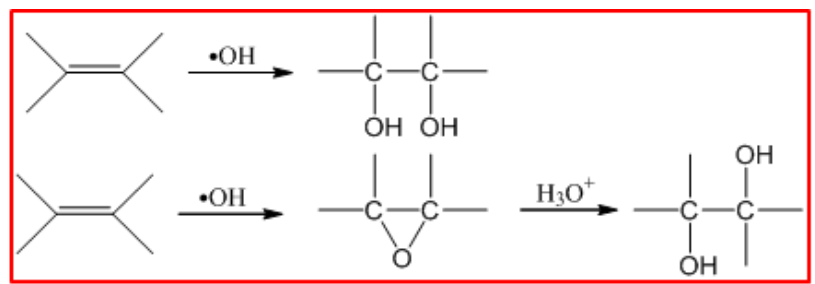

(b)

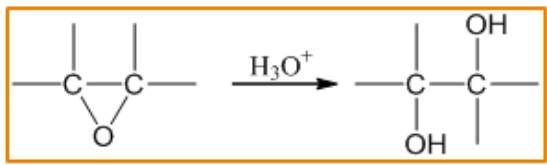

(c)
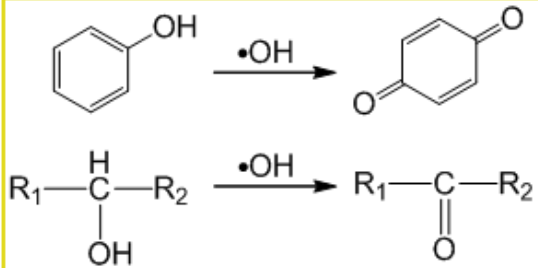

(d)

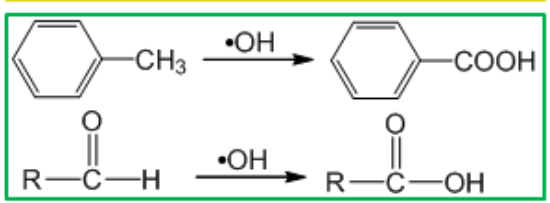

(1) Ruff degradation

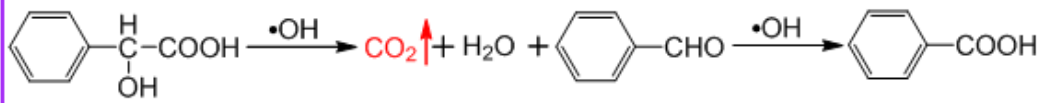

\section{(2) Vicinal diols cleavage}

(e)

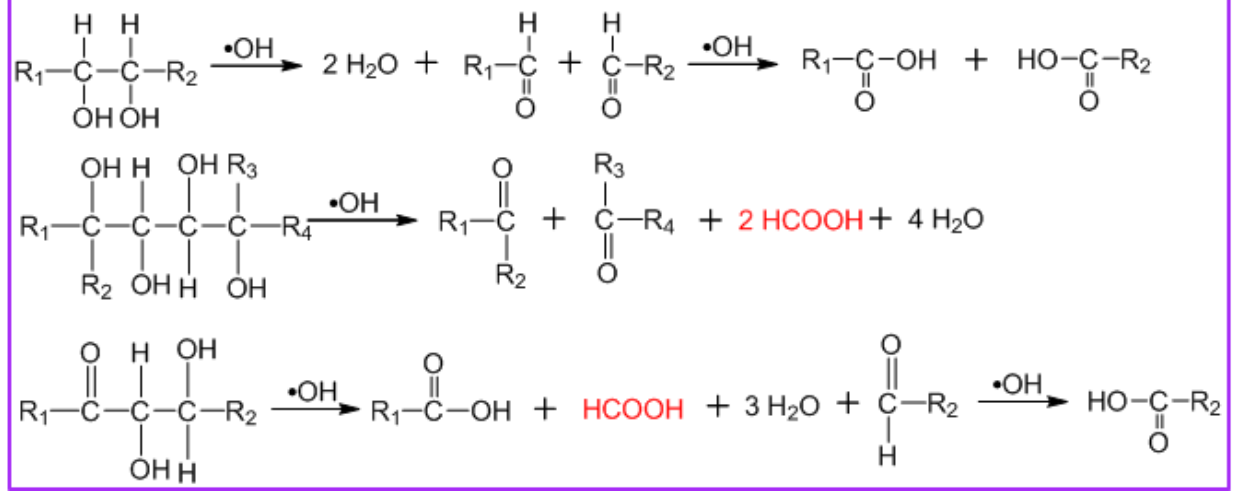

Figure S4. Proposed mechanism of oxidizing GO via SA-Fenton's reaction. (a) $\mathrm{C}=\mathrm{C}$ double bonds react with hydroxyl radicals by oxidative addition or hydroxylation reactions with epoxide as intermediates, resulting in C-C single bonds; (b) Epoxides react with water to form hydroxyl via ring opening reaction in acidic condition; (c) Phenols and alcohols are oxidized into quinones and ketones/aldehydes respectively; (d) The oxidation of either the side-chain adjacent to the aromatic moieties or the aldehyde groups at the edges of nanosheets into carboxylic groups; (e) The carbon atoms 
removal from the nanosheets by the oxidation of the side-chain carboxylic groups to release $\mathrm{CO}_{2}$ (eg. Ruff degradation) and vicinal diols cleavage reaction to generate small molecules. 


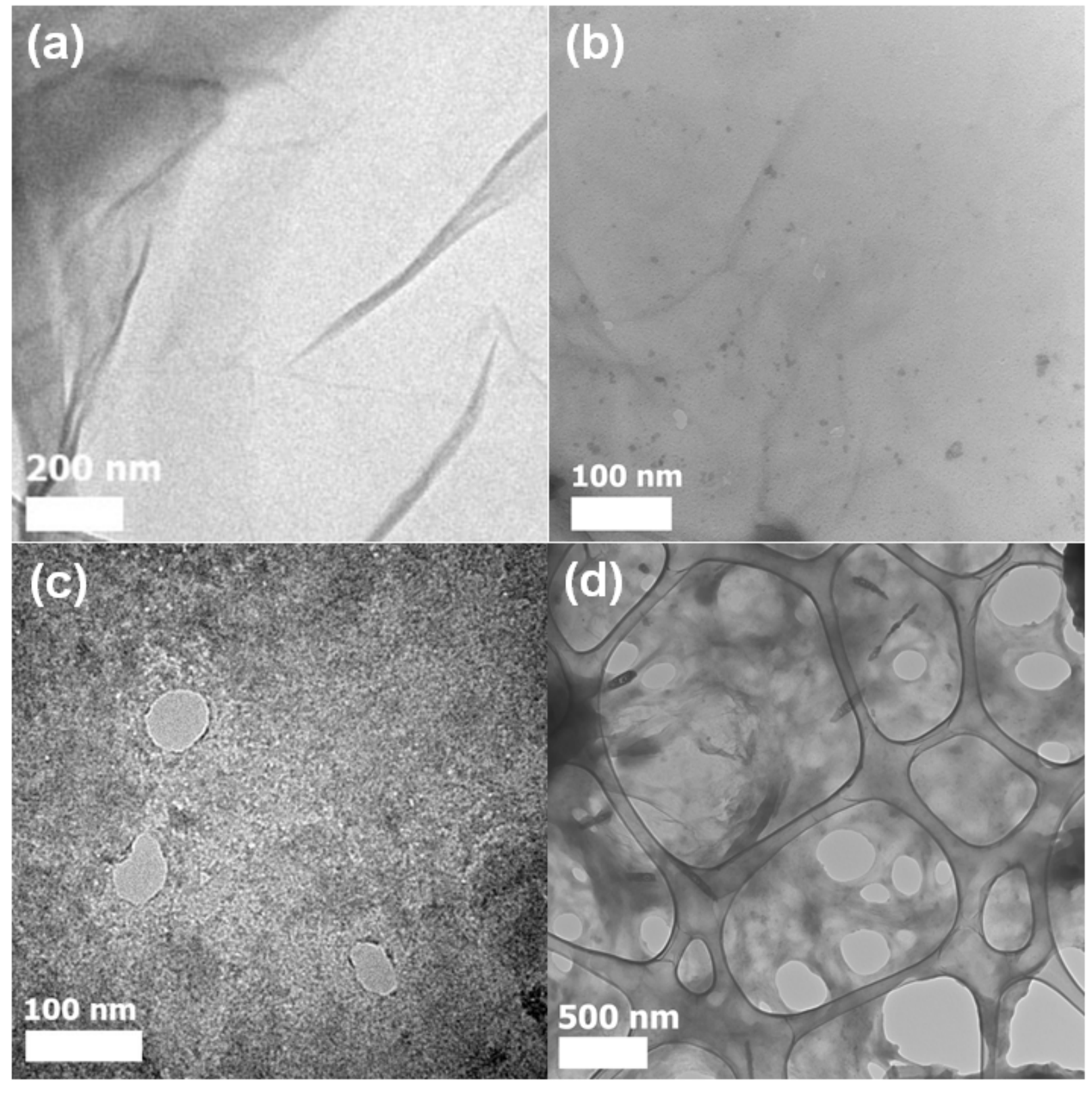

Figure S5. TEM images of GO nanosheets under the treatment of SA-Fenton's reaction for (a) $0 \mathrm{~h}$, (b) $8 \mathrm{~h}$, (c) $12 \mathrm{~h}$ and (d) $16 \mathrm{~h}$. 
(a)

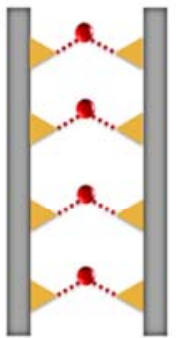

$\mathrm{WU}=\mathrm{Q}_{0}$

Graphene nanosheet

....... Water-sorption site hydrogen bond

(b)

$\mathrm{WU}=2 \mathrm{Q}_{0}$

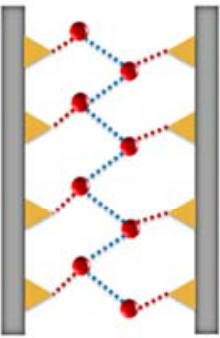

D Water sorption site

Water-water hydrogen bond
Water

(c)

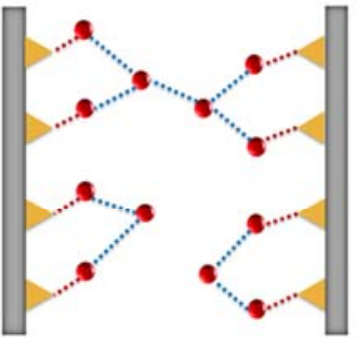

$W U=3 Q_{0}$

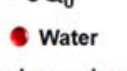

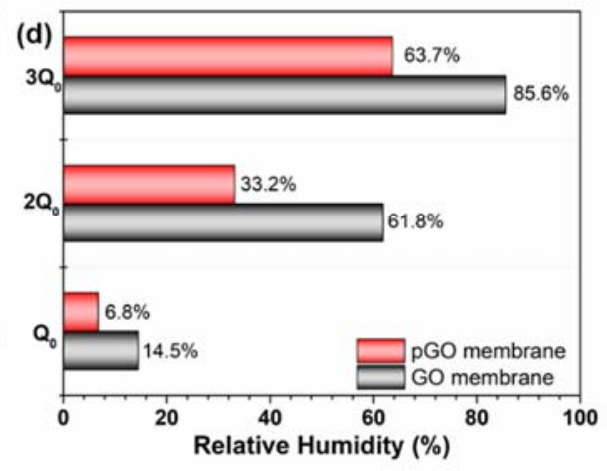

Figure S6. Schematic depicting the assumptions associated with using Park's Model for fitting the DVS isotherm when (a) $\mathrm{WU}=\mathrm{Q} 0$, (b) $\mathrm{WU}=2 \mathrm{Q} 0$, and (c) $\mathrm{WU}=3 \mathrm{Q} 0$. (d) Bar graph of active $\mathrm{Q} 0$ at different relative humidity for GO and pGO membrane. 


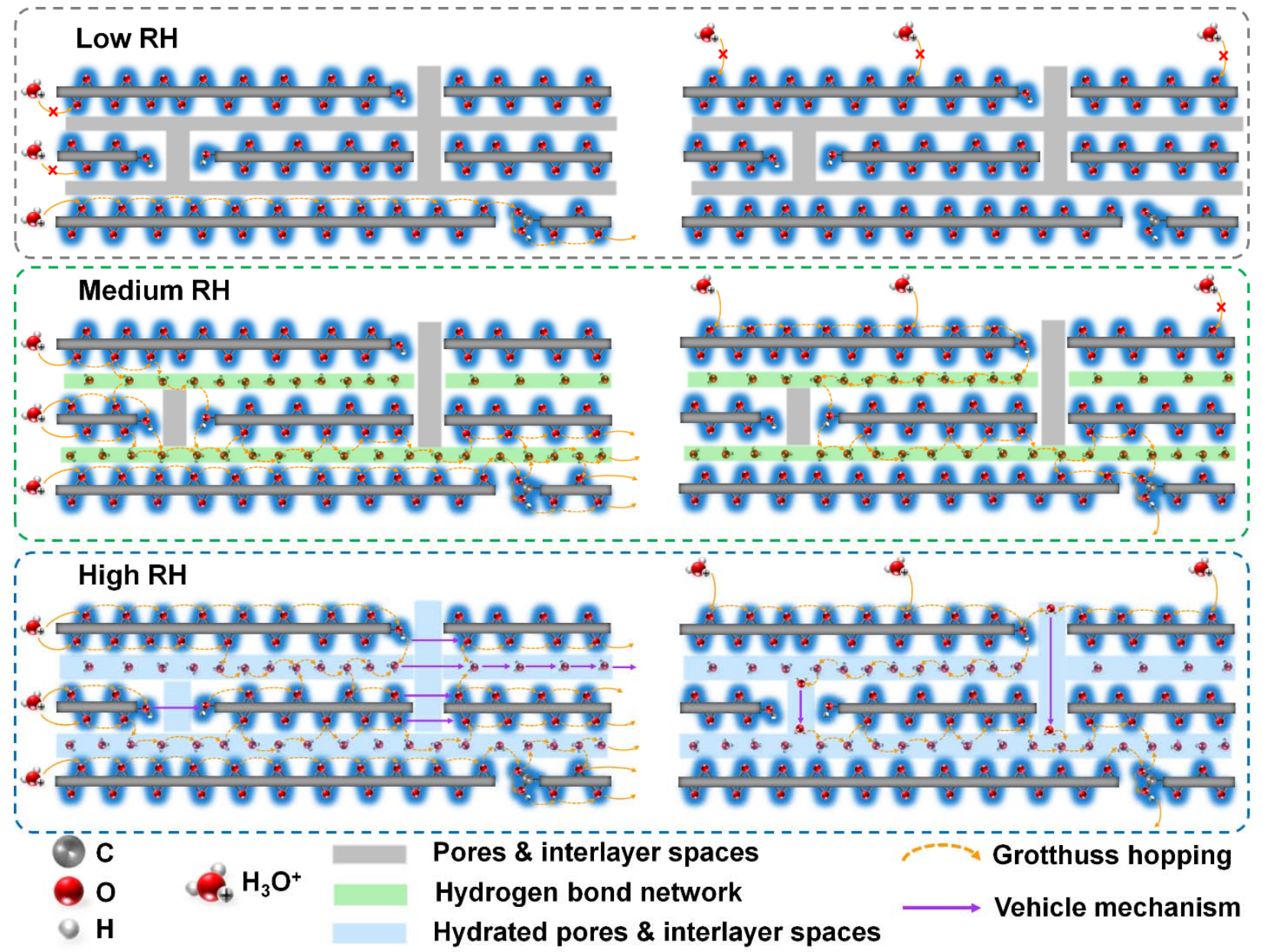

Figure S7. Proton conducting mechanisms in the in-plane (left) and through-plane (right) directions of a GO membranes at (a) low, (b) medium and (c) high RH. 
A typical AFCS operation begins with a constant air flow that is bubbled through an aqueous ethanol solution to simulate an ethanol-infused breath. Upon entering the AFCS (housing) chamber, the ethanol molecules will diffuse through the gas diffusion electrode to interact with catalyst on surface. Moreover, the ethanol will adsorb onto the $\mathrm{Pt} / \mathrm{C}$ catalyst triggering ethanol oxidation reaction (EOR) at the anode, and thereby releasing electrons and protons, and the by-product, acetic acid. The protons (oxonium ions) from the EOR migrate through the membrane to the cathode, while the electrons migrate through the external circuit to cathode. At the cathode, protons interact with electrons and oxygen, from the air, initiating oxygen reduction reaction (ORR) and generating water as the only product. The electrons that flowed through the external circuit are recorded and correlated to the ethanol concentration in vapor via the coulometric methodology.

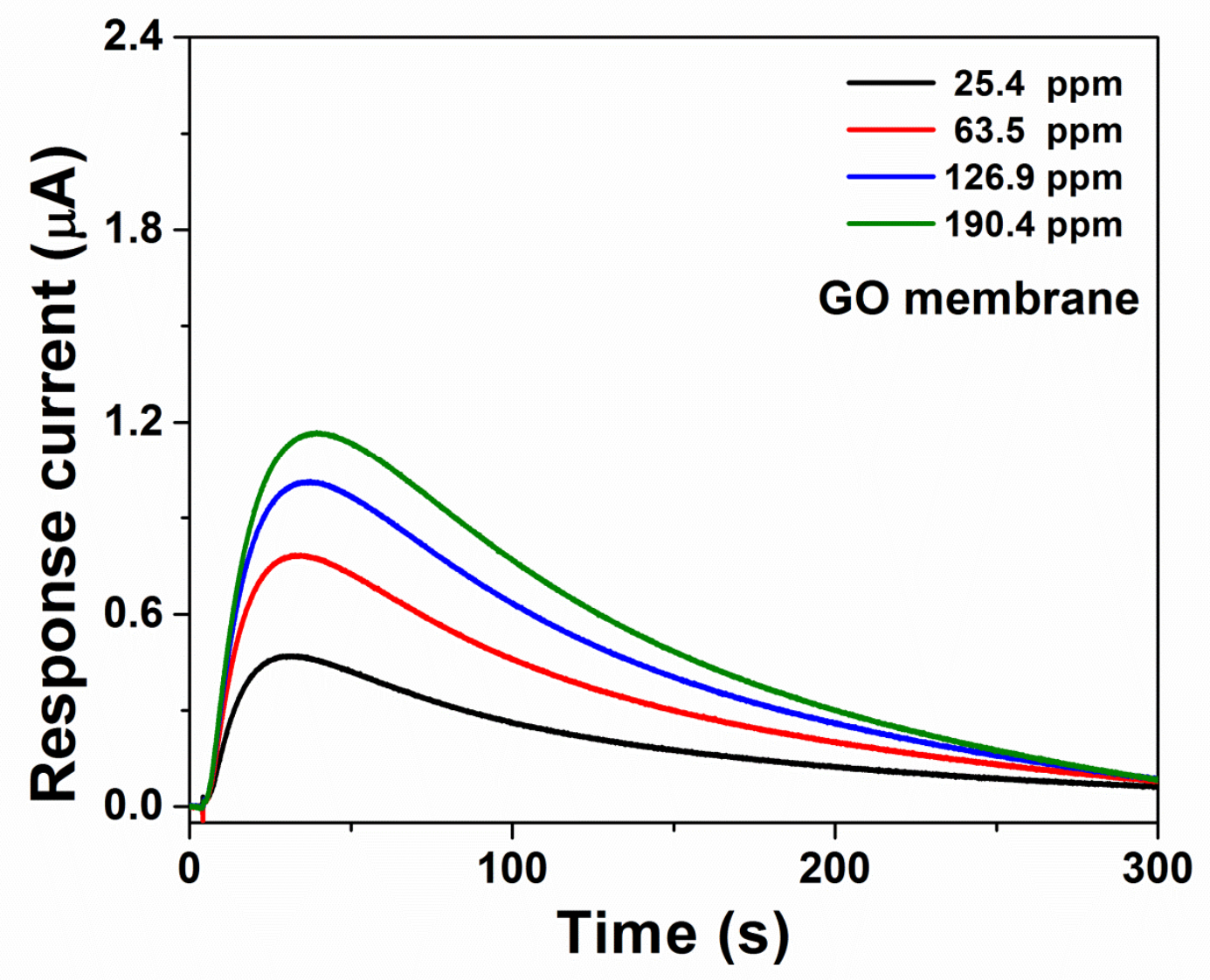

Figure S8. Response curves of GO-based AFCSs to ethanol vapor with different concentration. 


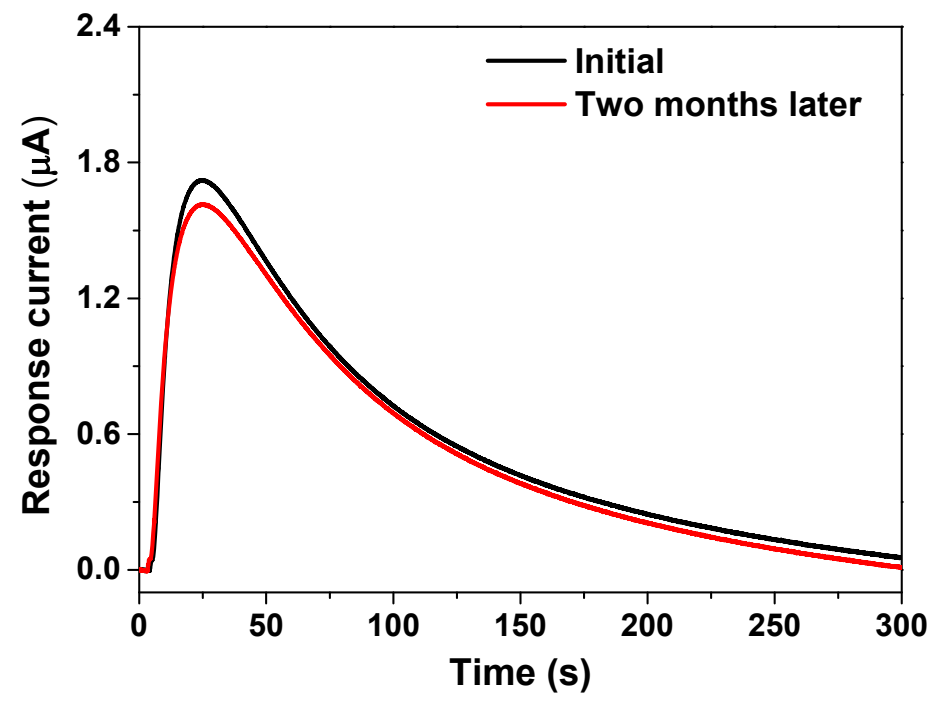

Figure S9. Ethanol response curves (at 190.4ppm) of AFCS equipped with a pGO membrane measured at initial and two months after the initial test 
Table S1. Table comparing pore-forming methodologies for GO

\begin{tabular}{|c|c|c|c|c|c|}
\hline Methodology & Precursors & Temperature & Scalable & Additional Notes & Ref \\
\hline Steam-Etching & GO, Water & $\begin{array}{c}200^{\circ} \mathrm{C} \\
\text { (hydrothermal) }\end{array}$ & $\begin{array}{c}\text { Very } \\
\text { Difficult }\end{array}$ & $\begin{array}{c}\text { Partially reduces } \\
\text { GO }\end{array}$ & 1 \\
\hline UV irradiation & $\mathrm{GO}, \mathrm{O}_{\underline{\underline{2}}}$ & Room Temp. & Difficult & $\begin{array}{l}\text { Partially reduces } \\
\text { GO }\end{array}$ & 2 \\
\hline Ozonation & $\mathrm{GO}, \mathrm{O}_{3}$ & Room Temp. & Easily & & 3 \\
\hline Annealing & rGO, Air & $400{ }^{\circ} \mathrm{C}$ & Difficult & & 4 \\
\hline $\begin{array}{c}\text { Microwave } \\
\text { Plasma }\end{array}$ & $\mathrm{rGO}, \mathrm{O}_{2}$ & Room Temp. & $\begin{array}{c}\text { Very } \\
\text { Difficult }\end{array}$ & & 4 \\
\hline UV irradiation & rGO & Room Temp. & Easily & & 4 \\
\hline $\begin{array}{c}\text { SA-Fenton's } \\
\text { reaction }\end{array}$ & $\begin{array}{l}\mathrm{GO}, \mathrm{H}_{2} \mathrm{O}_{2} \& \\
\text { Ferrous salt }\end{array}$ & Room Temp. & Very Easily & & This work \\
\hline
\end{tabular}


Table S2. Elemental composition of GO and pGO via EDX and XPS

\begin{tabular}{c|cc|cc}
\hline \multirow{2}{*}{ Element } & \multicolumn{2}{|c|}{ EDX } & \multicolumn{2}{c}{ XPS } \\
\cline { 2 - 5 } & GO & pGO & GO & pGO \\
\hline \multirow{2}{*}{ C } & $75.73 \%$ & $74.29 \%$ & $70.41 \%$ & $70.01 \%$ \\
\multirow{2}{*}{$\mathbf{O}$} & $24.27 \%$ & $25.71 \%$ & $29.59 \%$ & $29.99 \%$ \\
\hline
\end{tabular}


Table S3. Summary of data derived from XRD patterns and Raman spectra

\begin{tabular}{c|ccc|c|c}
\hline \multirow{2}{*}{ Sample } & \multicolumn{3}{|c|}{ XRD } & \multicolumn{2}{c}{ Raman } \\
\cline { 2 - 6 } & d-spacing, $\AA$ & $\mathbf{L}_{\mathbf{c}}$ & \# of Layers & $\mathbf{I}_{\mathbf{D}} / \mathbf{I}_{\mathbf{G}}$ & $\mathbf{A D}_{\mathbf{D}} / \mathbf{A}_{\mathbf{G}}$ \\
\hline \multirow{2}{*}{ GO } & 7.17 & 64.49 & 9.00 & 1.00 & 1.59 \\
pGO & 7.33 & 51.92 & 7.09 & 1.01 & 1.33 \\
\hline
\end{tabular}


Table S4. Table comparing the through-plane conductivity and anisotropy at room temperature of various works

\begin{tabular}{|c|c|c|c|c|c|}
\hline Membrane Type & $\begin{array}{l}\text { Thickness } \\
\qquad(\mu \mathrm{m})\end{array}$ & Relative Humidity & $\begin{array}{c}\text { Through-plane } \\
\text { Conductivity } \\
\left(\mathrm{mS} \mathrm{cm}{ }^{-1}\right)\end{array}$ & Anisotropy & Ref. \\
\hline GO & 29 & $95 \%$ & 0.18 & 10.51 & This work \\
\hline porous GO & 34 & $95 \%$ & 0.23 & 2.67 & This work \\
\hline GO & 22 & $95 \%$ & 0.86 & N/A & 3 \\
\hline Ozonated GO & 22 & $95 \%$ & 1.30 & N/A & 3 \\
\hline GO & 18 & $95 \%$ & 0.23 & 155 & 5 \\
\hline GO & 42 & $95 \%$ & 0.40 & N/A & 6 \\
\hline GO & Single-layer & $95 \%$ & 0.20 & N/A & 7 \\
\hline GO & $\sim 55$ & $30 \%$ & 0.40 & 5.63 & 8 \\
\hline GO & $\sim 55$ & $95 \%$ & 0.90 & 98 & 8 \\
\hline GO & 22 & $30 \%$ & 0.011 & 254.55 & 9 \\
\hline
\end{tabular}


Table S5. Summary of parameters and corresponding coefficient of determination from fitting Park's model to the DVS isotherms for GO and pGO membranes

\begin{tabular}{c|c|c|c|c|c|c}
\hline Membranes & $\begin{array}{c}\mathbf{Q}_{\mathbf{0}} \\
\left(\mathbf{m m o l} \mathbf{g}^{-1}\right)\end{array}$ & $\mathbf{K}_{\mathbf{L}}$ & $\begin{array}{c}\mathbf{K}_{\mathbf{H}} \\
\left(\mathbf{m m o l} \mathbf{g}^{-1}\right)\end{array}$ & $\begin{array}{c}\mathbf{K}_{\mathbf{A}} \\
\left(\mathbf{m m o l} \mathbf{g}^{-1}\right)\end{array}$ & $\mathbf{n}$ & $\mathbf{R}^{\mathbf{2}}$ \\
\hline GO & 5.88 & 23.02 & 9.41 & 1.70 & 6.83 & 0.9994 \\
pGO & 4.91 & 54.36 & 15.59 & 2.17 & 14.65 & 0.9980 \\
\hline
\end{tabular}




\section{References}

1. Han, T. H.; Huang, Y.-K.; Tan, A. T.; Dravid, V. P.; Huang, J., Steam Etched Porous Graphene Oxide Network for Chemical Sensing. J. Am. Chem. Soc. 2011, 133, 15264-15267.

2. Koinuma, M.; Ogata, C.; Kamei, Y.; Hatakeyama, K.; Tateishi, H.; Watanabe, Y.; Taniguchi, T.; Gezuhara, K.; Hayami, S.; Funatsu, A., Photochemical Engineering of Graphene Oxide Nanosheets. J. Phys. Chem. C 2012, 116, $19822-19827$.

3. Gao, W.; Wu, G.; Janicke, M. T.; Cullen, D. A.; Mukundan, R.; Baldwin, J. K.; Brosha, E. L.; Galande, C.; Ajayan, P. M.; More, K. L., Ozonated Graphene Oxide Film As a Proton-Exchange Membrane. Angew. Chem. Int. Ed. 2014, 53, 3588-3593.

4. Solís-Fernández, P.; Paredes, J.; Villar-Rodil, S.; Guardia, L.; Fernández-Merino, M.; Dobrik, G.; Biró, L.; Martínez-Alonso, A.; Tascón, J., Global and Local Oxidation Behavior of Reduced Graphene Oxide. J. Phys. Chem. C 2011, 115, 7956-7966.

5. Bayer, T.; Selyanchyn, R.; Fujikawa, S.; Sasaki, K.; Lyth, S., Spray-Painted Graphene Oxide Membrane Fuel Cells. J. Membr. Sci. 2017, 541, 347-357.

6. Bayer, T.; Bishop, S.; Nishihara, M.; Sasaki, K.; Lyth, S., Characterization of a Graphene Oxide Membrane Fuel Cell. J. Power Sources 2014, 272, 239-247.

7. Hatakeyama, K.; Karim, M. R.; Ogata, C.; Tateishi, H.; Funatsu, A.; Taniguchi, T.; Koinuma, M.; Hayami, S.; Matsumoto, Y., Proton Conductivities of Graphene Oxide Nanosheets: Single, Multilayer, and Modified Nanosheets. Angew. Chem. 2014, 126, 7117-7120.

8. Tateishi, H.; Hatakeyama, K.; Ogata, C.; Gezuhara, K.; Kuroda, J.; Funatsu, A.; Koinuma, M.; Taniguchi, T.; Hayami, S.; Matsumoto, Y., Graphene Oxide Fuel Cell. J. Electrochem. Soc. 2013, 160, F1175.

9. $\quad$ Gao, W.; Singh, N.; Song, L.; Liu, Z.; Reddy, A. L. M.; Ci, L.; Vajtai, R.; Zhang, Q.; Wei, B.; Ajayan, P. M., Direct Laser Writing of Micro-Supercapacitors on Hydrated Graphite Oxide Films. Nat. Nanotechnol. 2011, 6, 496. 